\title{
Composição química e potencial antifúngico do óleo essencial de jambu sob adubação orgânica e convencional
}

O jambu (Spilanthes oleracea L.) pertence à família Asteraceae, nativa da Amazônia, de clima tropical. Essa planta é uma hortaliça bastante cultivada e consumida na região Norte do Brasil, principalmente no Pará. Algumas de suas formas de utilização são nos restaurantes de comidas exóticas utilizando a inflorescência de jambu para compor seus pratos diferenciados na gastronomia. Entretanto o maior interesse nesta cultura é devido ao seu óleo essencial amplamente utilizado nas indústrias cosméticas e farmacêuticas. Nesta pesquisa, objetivou-se a obtenção e caracterização do óleo essencial de jambu cultivado de modo orgânico e convencional e seu possível efeito fungicida. O óleo essencial de folhas e inflorescências de duas cultivares (Jambuarana e Nazaré) foi obtido pela técnica de 'arraste a vapor d'água', usando um aparelho de Clevenger modificado e submetido, posteriormente, à análise por CG acoplada a um espectrômetro de massas CG-EM, a fim de analisar sua composição química. Além disso, foi testada a atividade antifúngica sobre Aspergillus niger. O óleo de Spilanthes oleracea mostra diferenças entre as cultivares e entre os órgãos estudados, em função de sua fenologia. O maior potencial antifúngico observado foi obtido de inflorescências da cv. Nazaré orgânica. Esta espécie é promissora produtora de óleos essenciais de alto valor agregado.

\section{Chemical composition and antifungal potential of jambu essential oil under organic and conventional fertilization}

\begin{abstract}
The jambu (Spilanthes oleracea L.) belongs to the Asteraceae family, native to the Amazon, with a tropical climate. This plant is a vegetable widely cultivated and consumed in the Northern region of Brazil, mainly in Pará. Some of its uses are in exotic food restaurants using the inflorescence of jambu to compose its differentiated dishes in gastronomy. However, the greatest interest in this culture is due to its essential oil widely used in the cosmetic and pharmaceutical industries. Because of this factor research aimed to obtaining and characterization of essential oil jambu grown organically and conventional fungicide and its possible effect. The essential oil from leaves and flowers of the two cultivars (Jambuarana and Nazareth) was obtained by the technique of 'drag the water vapor', using a modified Clevenger apparatus and subjected subsequently analyzed by GC coupled to a mass spectrometer GC-MS in order to analyze their chemical composition. Furthermore, we tested the antifungal activity against Aspergillus niger. The oil Spilanthes oleracea shows differences among cultivars and among the organs studied, due to its phenology. The highest antifungal potential of inflorescences observed was obtained from cv. Nazareth organic. This species is promising producer of essential oils with high added value.
\end{abstract}

Keywords: Aspergillus niger; CG/MS; Essential oil; Spilanthes oleracea L.

Topic: Desenvolvimento, Sustentabilidade e Meio Ambiente

Reviewed anonymously in the process of blind peer.
Received: 01/01/2021

Approved: 28/01/2021
Luciana da Silva Borges (10)

Universidade Federal Rural da Amazônia, Brasil

http://lattes.cnpq.br/4533722536181534

http://orcid.org/0000-0002-1194-6411

luciana.borges@ufra.edu.br

Clarissa Hamaio Okino Delgado (iD)

Centro Universitário de Rio Preto, Brasil

http://lattes.cnpq.br/4811006629012291

http://orcid.org/0000-0002-8750-7298

clarissaokino@gmail.com

Luana Keslley Nascimento Casais (iD

Universidade Federal Rural da Amazônia, Brasil

http://lattes.cnpq.br/8075409193627849

http://orcid.org/0000-0001-7197-5524

luana.casais@gmail.com

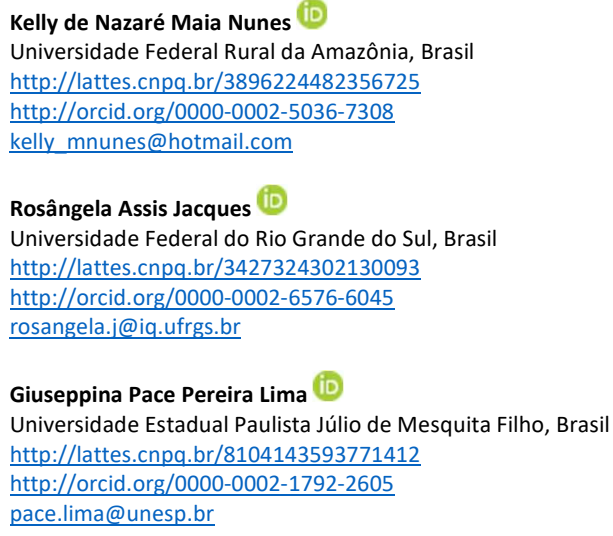

Referencing this:

BORGES, L. S.; DELGADO, C. H. O.; CASAIS, L. K. N.; NUNES, K. N. M.; JACQUES, R. A.; LIMA, G. P. P.. Composição química e potencial antifúngico do óleo essencial de jambu sob adubação orgânica e convencional. Revista Ibero Americana de Ciências Ambientais, v.12, n.1, p.461-470, 2021. DOI: http://doi.org/10.6008/CBPC2179$\underline{6858.2021 .001 .0037}$ 


\section{INTRODUÇÃO}

O jambu (Spilanthes oleracea L.) pertence à família Asteraceae, nativa da Amazônia, de clima tropical. Essa planta é uma hortaliça bastante cultivada e consumida na região Norte do Brasil, principalmente no Pará. Segundo Borges et al. (2014) essa planta, por apresentar propriedades químicas, vem despertando o interesse das empresas farmacêuticas e de cosméticos que as utilizam como matéria prima para seus produtos. Outras formas de utilização são nos restaurantes de comidas exóticas utilizando a inflorescência de jambu para compor seus pratos diferenciados na gastronomia. Popularmente essa planta é utilizada como erva medicinal, sendo sugerido como antibiótico e anestésico (BORGES et al., 2013).

Segundo Lorenzi et al. (2002), o jambu possui em torno de 0,7 \% de óleo essencial, que está sendo fornecido direto para as indústrias de cosméticos, pela sua qualidade farmacológica. Esse efeito farmacológico se deve as suas substâncias químicas, dentre as quais, trans-cariofileno, germacreno D, Ldodeceno, espatulenol e espilantol (BORGES et al., 2012). Essa planta por apresentar propriedades químicas, vem despertando o interesse das empresas farmacêuticas e de cosméticos que as utilizam como matéria prima para seus produtos.

Substâncias presentes em óleos essenciais de diversas plantas podem apresentar atividade fungicida (ZUZARTE et al., 2012) e o aumento da incidência de infestações causadas por fungos em alimentos tem levado a uma busca constante por alternativas naturais eficazes que possam oferecer melhores opções de tratamento. Alimentos, processados ou crus são materiais vulneráveis a contaminação por fungos, em particular por Aspergillus spp., a maior causa de contaminação de alimentos em países tropicais (WHITFIELD, 2004).

Deste modo, um estudo detalhado sobre a atividade antifúngica do óleo essencial de espécies Spilanthes oleracea L. (Jambu) é importante para sua validação como substância que pode ser usada na industria de alimentos, como possível coadjuvante na sanitização. Com isso, o objetivo deste trabalho foi determinar a composição química do óleo essencial de diferentes partes de duas cultivares de jambu cv. Jambuarana e cv. Nazaré, cultivadas de modo orgânico ou convencional, por cromatografia gasosa acoplada a espectrometria de massa e avaliar seu potencial antifúngica sobre A. niger.

\section{MATERIAIS E MÉTODOS}

\section{Obtenção da planta}

O experimento foi conduzido em túnel construído com estrutura metálica em arco, com $60 \mathrm{~m}$ de comprimento e 6 de largura, totalizando uma área de $360 \mathrm{~m}^{2}$, apresentando pé direito de $2 \mathrm{~m}$. A parte superior foi revestida com filme de polietileno de baixa densidade (PEBD) transparente aditivado anti-UV, com 0,1 mm de espessura, em Botucatu-SP, com coordenadas geográficas latitude $22^{\circ} 44^{\prime} 50^{\prime \prime}$ sul e longitude $48^{\circ} 34^{\prime} 00^{\prime \prime}$ oeste de Greenwich, com altitude em torno de $765 \mathrm{~m}$. 


\section{Cultivo do jambu}

A semeadura foi realizada em bandejas de poliestireno expandido de 128 células, contendo o substrato comercial Plantmax ${ }^{\circledast}$. Em cada célula foram colocadas cinco sementes de Jambu cv. Jambuarana ou cv. Nazaré. A emergência ocorreu aos sete dias e o desbaste deixou uma plântula por célula. O transplante foi realizado aos 40 dias após a semeadura, manualmente, quando as mudas se apresentavam com seis folhas definitivas, em quatro canteiros de $6 \mathrm{~m}^{2}$, colocando-se 18 plantas por linha e cada canteiro constou de cinco linhas. $O$ espaçamento utilizado foi de $20 \times 25 \mathrm{~cm}$.

Para adubação orgânica aplicou-se $8 \mathrm{~kg} / \mathrm{m}^{-2}$ de esterco de curral no plantio e para adubação em cobertura foram realizadas aplicações parceladas de $1 \mathrm{~kg} / \mathrm{m}^{2}$ de torta de mamona aos 55,70 e 80 dias após o transplante de plantas de jambu. Para a adubação mineral utilizou-se $120 \mathrm{~g} / \mathrm{m}^{-2}$ de nitrato de amônia, 200 $\mathrm{g} / \mathrm{m}^{-2}$ de superfosfato simples e $50 \mathrm{~g} / \mathrm{m}^{-2}$ de cloreto de potássio no plantio e para a adubação em cobertura aplicou-se $50 \mathrm{~g} / \mathrm{m}^{-2}$ de NPK na formulação de $(15,15,20)$, aos 55,70 e 80 dias após o transplante.

A colheita foi feita pela manhã, aos 90 dias após a semeadura, na abertura do botão floral. Os ramos foram cortados a sete $\mathrm{cm}$ do solo. As plantas de jambu foram lavadas, separadas em folhas e inflorescência, levadas ao laboratório para secagem em estufa de circulação forçada de ar, a $40{ }^{\circ} \mathrm{C}$, até peso constante e em seguida foram moídas em moinho de aço-inox, tipo Wiley.

\section{Extração do óleo essencial}

As folhas e as inflorescências secas foram moídas e submetidas, separadamente, a hidro-destilação em aparelho de Clevenger por duas horas, para a obtenção dos óleos essenciais. Os óleos obtidos foram separados da fase aquosa por partição líquido-líquido com diclorometano.

\section{A separação e a quantificação: Análise cromatografia gasosa acoplada à espectrometria de massas (CG- EM)}

As análises empregando cromatografia gasosa acoplada à espectrometria de massas (CG-EM) foram realizadas no cromatógrafo gasoso (GC-QP2010 PLUS, Shimadzu, Kyoto, Japão) acoplado com espectrômetro de massas (QP 2010 PLUS), usando uma coluna capilar de sílica fundida OV-5 (5\% de fenildimetilpolysiloxano), (60 m de comprimento $\times 0,25 \mathrm{~mm}$ diâmetro, 0,10 $\mu \mathrm{m}$ de espessura de filme), sob as seguintes condições: gás carregador de hélio (99,999\% e velocidade de fluxo de 1,0 mL min$\left.{ }^{-1}\right)$; volume de

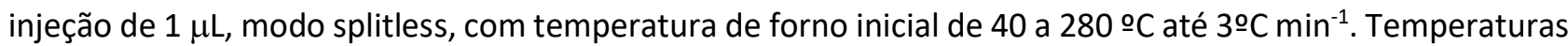
do injetor, detector de quadrupolo e da linha de transferência foram de 280 으. Os parâmetros de varredura do MS incluíram voltagem de ionização de impacto de elétron de $70 \mathrm{eV}$, uma faixa de massa de 45 a $700 \mathrm{~m} / \mathrm{z}$ e um intervalo de varredura de $0,2 \mathrm{~s}$. Os índices de retenção foram calculados usando uma mistura de nalcanos $\left(\mathrm{C}_{8}-\mathrm{C}_{28}\right)$ como referência externa.

\section{Identificação das substâncias}

A identificação das substâncias foi efetuada através da comparação dos seus espectros de massas 
com o banco de dados do sistema CG-EM (NIST 2.0) e índice de retenção de Kovats (ADAMS, 2001).

\section{Atividade antimicrobiana in vitro}

Óleo essencial do jambu foi levado ao laboratório de microbiologia do Departamento de Química e Bioquímica, do IBB, UNESP, campus de Botucatu, para verificação da sua atividade antifúngica.

\section{Obtenção de isolados do patógeno}

Placas de Petri contendo ágar Müeller-Hinton foram inoculadas com fungo Aspergillus niger. As colônias fúngicas foram transferidas para placas de Petri, contendo meio de cultura BDA, com auxílio de estilete, em câmara de fluxo e condições assépticas (TUITE, 1969).

Alíquotas do óleo essencial $(5 \mu \mathrm{L})$ do jambu foi incorporado sobre superfície do ágar das placas inoculadas para a constituição dos tratamentos. As placas foram incubadas em câmara de crescimento com temperatura controlada para $25 \pm 1{ }^{\circ} \mathrm{C}$, em ausência de luz. As avaliações do experimento foram realizadas diariamente, através de observação do crescimento micelial.

\section{RESULTADOS E DISCUSSÃO}

\section{Quantificação e qualificação do óleo essencial}

No óleo de ambas cultivares, dos dois modos de cultivo, tanto em folhas, como inflorescências, verificou-se a presença de 27 compostos, perfazendo um total de 64,82 \%. Na Tabela 1 estão apresentados os dados médios da composição química obtida nos órgãos das cultivares estudadas, dos dois modos de cultivo. Na análise por CG-MS, verifica-se que os compostos majoritários foram cis- $\beta$-guaieno, carotol, $\beta$ acarenol, dictamnole, flavenosa, drima-7,9(11)-dieno e leptospermone. Esses resultados diferem de outros relatos com jambu (BORGES et al., 2012; DIAS et al., 2012). Outros estudos prévios, com outras espécies, mostram que a composição do óleo é dependente de fatores abióticos e bióticos (BERTOLI et al., 2003; CAKIR et al., 2005). Borges et al. (2014), obtiveram no óleo essencial de plantas de jambu, cv. Jambuarana a presença de 66 substâncias, perfazendo um total de $98.25 \%$ do óleo essencial. Sendo os compostos majoritários encontrados, $\beta$-Myrcene, Dictamnol, Germacrene D e $\beta$-Pinene.

Tabela 1: Composição química de óleo essencial de Spilanthes oleraceae L.

\begin{tabular}{llllll}
\hline Picos & Compostos & t ret & Área $\%$ & Índice calculado & IK lit. \\
\hline $\mathbf{1}$ & Evadone & $\mathbf{3 3 , 7 5 0}$ & $\mathbf{0 , 1 0}$ & $\mathbf{1 3 4 1}$ & $\mathbf{( 1 3 4 0 )}$ \\
\hline $\mathbf{2}$ & Dictamnol & $\mathbf{3 7 , 5 0 6}$ & $\mathbf{4 , 9 5}$ & $\mathbf{1 4 2 9}$ & $\mathbf{( 1 4 3 0 )}$ \\
\hline $\mathbf{3}$ & v-Elemene & 37,967 & 0,26 & 1440 & $(1437)$ \\
\hline $\mathbf{4}$ & Dehydro aromadrendane & 38,921 & 0,49 & 1463 & $(1463)$ \\
\hline $\mathbf{5}$ & Drima-7, 9(11)-diene & $\mathbf{3 9 , 3 8 2}$ & $\mathbf{3 , 0 9}$ & $\mathbf{1 4 7 4}$ & $\mathbf{( 1 4 7 3 )}$ \\
\hline $\mathbf{6}$ & Germacrene D & $\mathbf{4 0 , 0 3 9}$ & $\mathbf{0 , 2 9}$ & $\mathbf{1 4 9 0}$ & $\mathbf{( 1 4 8 5 )}$ \\
\hline $\mathbf{7}$ & Cis -beta guaiene & $\mathbf{4 0 , 1 3 8}$ & $\mathbf{1 3 , 0 6}$ & $\mathbf{1 4 9 3}$ & $\mathbf{( 1 4 9 3 )}$ \\
\hline $\mathbf{8}$ & Valencene & 40,331 & 0,90 & 1497 & $(1496)$ \\
\hline $\mathbf{9}$ & Epizonarene & 40,509 & 0,38 & 1502 & $\mathbf{( 1 5 0 2 )}$ \\
\hline $\mathbf{1 0}$ & a-Cadinene & 41,942 & 0,93 & 1539 & $\mathbf{( 1 5 3 9 )}$ \\
\hline $\mathbf{1 2}$ & Flavesone & $\mathbf{4 2 , 2 0 5}$ & $\mathbf{4 , 7 6}$ & $\mathbf{1 5 4 6}$ & $\mathbf{( 1 5 4 7 )}$ \\
\hline $\mathbf{1 3}$ & Nerolidol & 42,901 & 1,11 & 1563 & $\mathbf{( 1 5 6 3 )}$ \\
\hline
\end{tabular}




\begin{tabular}{|c|c|c|c|c|c|}
\hline 14 & Viridiflorol & 44,034 & 0,79 & 1593 & (1593) \\
\hline 15 & Carotol & 44,134 & 8,86 & 1595 & (1595) \\
\hline 16 & Guaiol & 44,263 & 0,37 & 1599 & (1601) \\
\hline 17 & Leptospermone & 45,134 & 3,06 & 1622 & (1623) \\
\hline 18 & $\beta$ - acorenol & 45,772 & 7,04 & 1639 & (1637) \\
\hline 19 & Helifolenol D & 47,316 & 2,27 & 1681 & (1682) \\
\hline 20 & Acorenone B & 47,925 & 1,77 & 1698 & (1698) \\
\hline 21 & Capalponone & 54,608 & 1,38 & 1894 & (1894) \\
\hline 22 & Toterene & 55,417 & 1,75 & 1920 & (1923) \\
\hline 23 & Pimaradiene & 56,355 & 0,64 & 1950 & (1950) \\
\hline 24 & Palmitic acid & 56,760 & 1,27 & 1962 & \\
\hline 25 & Laurenan-2-one & 61,409 & 1,04 & 2116 & (2016) \\
\hline 26 & Incensole & 62,619 & 1,93 & 2158 & (2159) \\
\hline 27 & C25H52 & 71,703 & 1,16 & 2500 & \\
\hline \multicolumn{3}{|c|}{ Total } & 64,82 & & \\
\hline
\end{tabular}

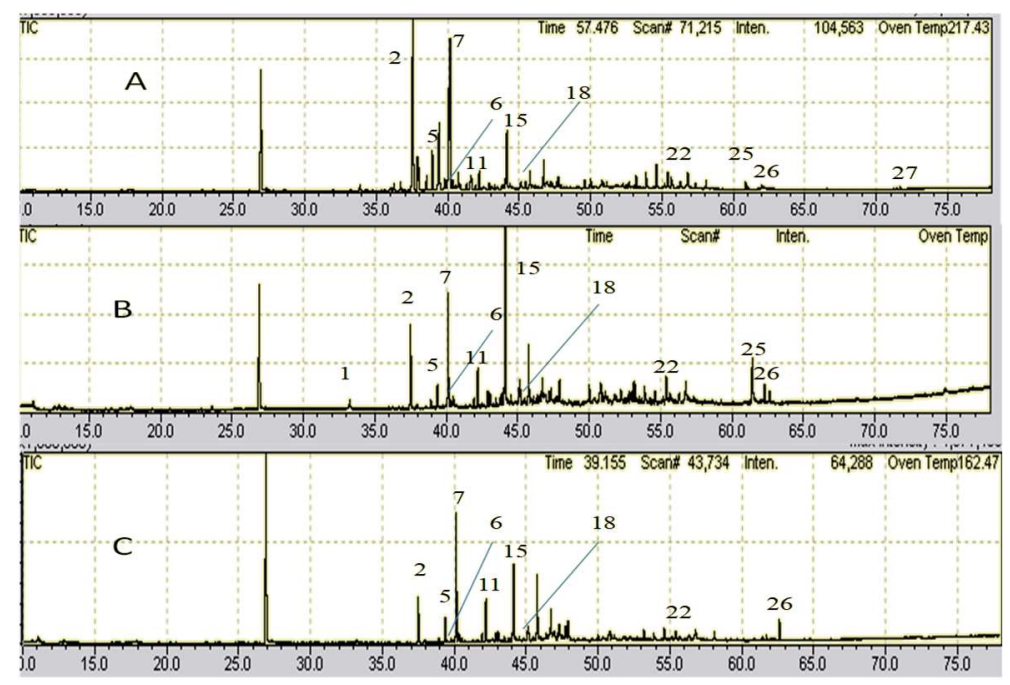

Figura 1: Cromatogramas do íon total dos óleos obtidos das amostras de Inflorescência (A), Folha (B) e Talo (C) de jambu convencional, cv. Jambuarana. (1) Evadone, (2) Dictamnol, (5) Drima-7, 9(11) -diene, (6) Germacrene D, (7) Cis beta guaiene, (11) Flavesone, (15) Carotol, (17) Leptospermone, (18) $\beta$ - acorenol, (22) Toterene, (25) Laurenan-2-one,

(26) Incensole, (27) C25H52.

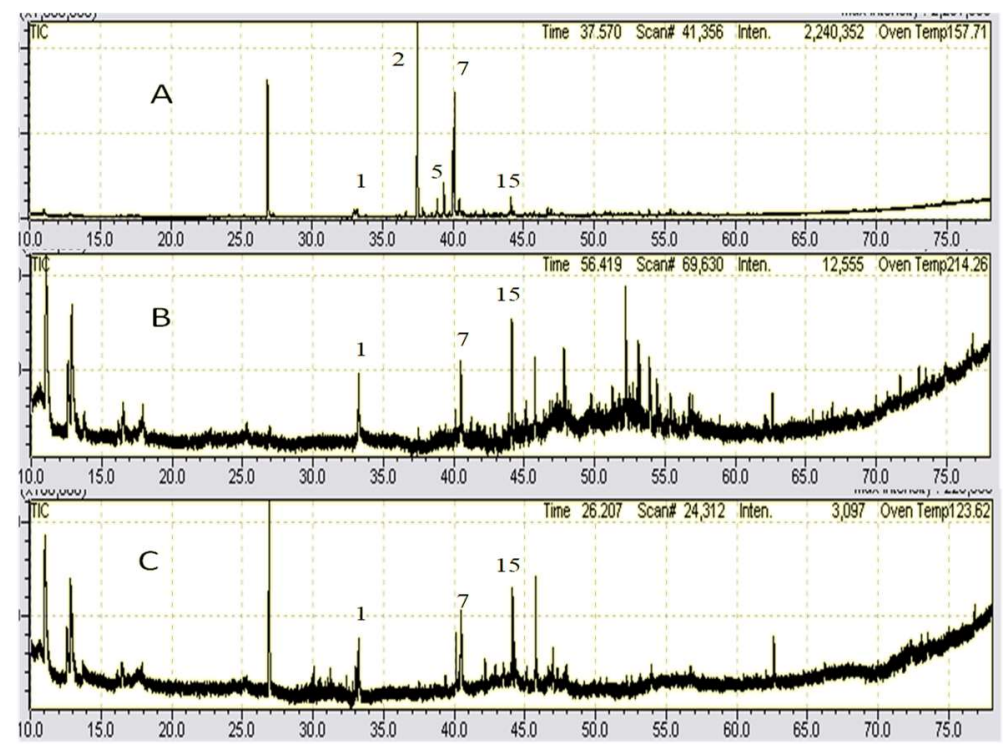

Figura 2: Cromatogramas do íon total dos óleos obtidos das amostras de Inflorescência (A), Folha (B) e Talo (C) de jambu orgânico, cv. Jambuarana. (1) Evadone, (2) Dictamnol, (5) Drima-7, 9(11)-diene, (7) Cis -beta guaiene, (15) Carotol.

Comparando as figuras 1 e 2, onde se tem os cromatogramas dos óleos obtidos das inflorescências da cv. Jambuarana nota-se que o modo de cultivo orgânico ou convencional pode ter induzido diferenciação, 
assim como entre os órgãos analisados. A substância Evadone (pico 1) ocorre nas folhas, mas não foi verificado nas inflorescências e talos cv. Jambuarana. Maior pico, consequentemente, maior teor de Dictamol (pico 2) ocorre nas inflorescências, seguida das folhas e talos cultivados de modo convencional (Figura 1). Como sugerido por Mapeli et al. (2005), as plantas devem ser comparadas e contrastadas, porque nutrientes em excesso, ou deficiência, pode intervir na produção de biomassa e a quantidade de seus princípios ativos.

A substância Evadone, pico 1, ocorre nas folhas e talos, e em menor intensidade nas inflorescências na cv. jambuarana em adubação orgânica. Enquanto que a substância Dictamol, pico 2, apresentou maior pico nas inflorescências, e não foi observado nas folhas e talos da cv. Jambuarana orgânica (Figura 2). Germacreno D, pico 6 (Figura 2), não foi identificado nos órgãos vegetais da cv. Jambuarana, cultivadas sob adubação orgânica. Dados de literatura indicam que altas temperaturas, como as utilizadas na extração dos óleos essenciais por hidrodestilação, podem levar à degradação do germacreno $D$ ou induzir um rearranjo molecular, originando outros compostos de natureza sesquiterpenoídica, considerados artefatos (RADULOVIC et al., 2007). Segundo Blank et al. (2005), a qualidade do óleo essencial é muito importante para o mercado de importação/exportação e sua análise química é necessária. Dessa forma, os tipos de cultivo serão importantes para a presença de algum composto, como o Germacreno $D$, que não ocorre em jambu orgânico. Borges et al. (2014), obtiveram no óleo de essencial de jambu, 7,98 \% de Germacrene D na cv. Jambuarana.

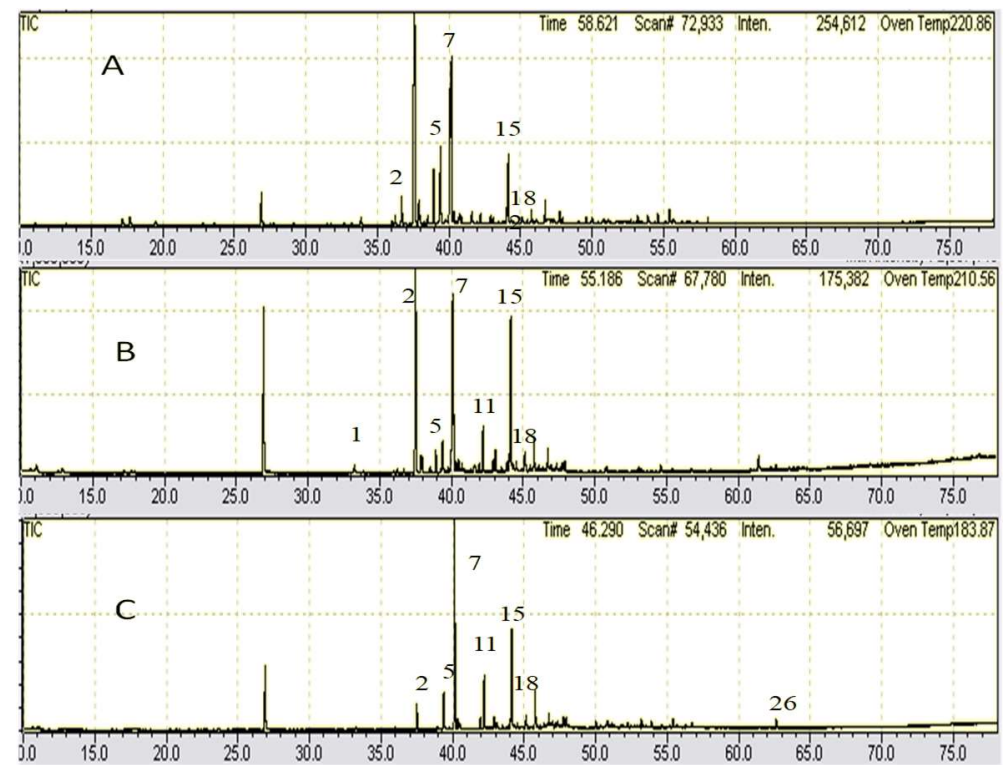

Figura 3: Cromatogramas do íon total dos óleos obtidos das amostras de Inflorescência (A), Folha (B) e Talo (C) de jambu convencional, cv. Nazaré. (1) Evadone, (2) Dictamnol, (5) Drima-7, 9(11) -diene, (7) Cis -beta guaiene, (11) Flavesone, (15) Carotol, (17) Leptospermone, (18) $\beta$ - acorenol, (26) Incensole.

Ocorrem compostos no óleo da folha cv. Nazaré em adubação orgânica, que não aparecem nas inflorescências e talos, como o Evadone, pico 1 (Figura 3). Os óleos essenciais são, de uma maneira geral, uma mistura muito complexa de hidrocarbonetos, álcoois e aromáticos, encontrados em todo tecido vivo de plantas, em geral concentrados na casca, nas flores, nas folhas, nos rizomas e nas sementes (ARAÚJO, 1995; BURT, 2004). Embora todos os órgãos de uma planta possam acumular óleos voláteis, sua composição pode variar segundo a localização, como por exemplo, o óleo das cascas da canela é rico em aldeído cinâmico, enquanto que o das folhas e das raízes desse mesmo vegetal são ricos em eugenol e cânfora, 
respectivamente. Também a composição química de um óleo volátil, extraído de um mesmo órgão de uma mesma espécie vegetal, pode variar significativamente, de acordo com a época de coleta, condições climáticas e de solo (SIMÕES et al., 1999). Também são muito conhecidos desde a Antiguidade por possuir atividade biológica, por suas propriedades antibacteriana, antifúngica e antioxidante (CAKIR et al., 2005).

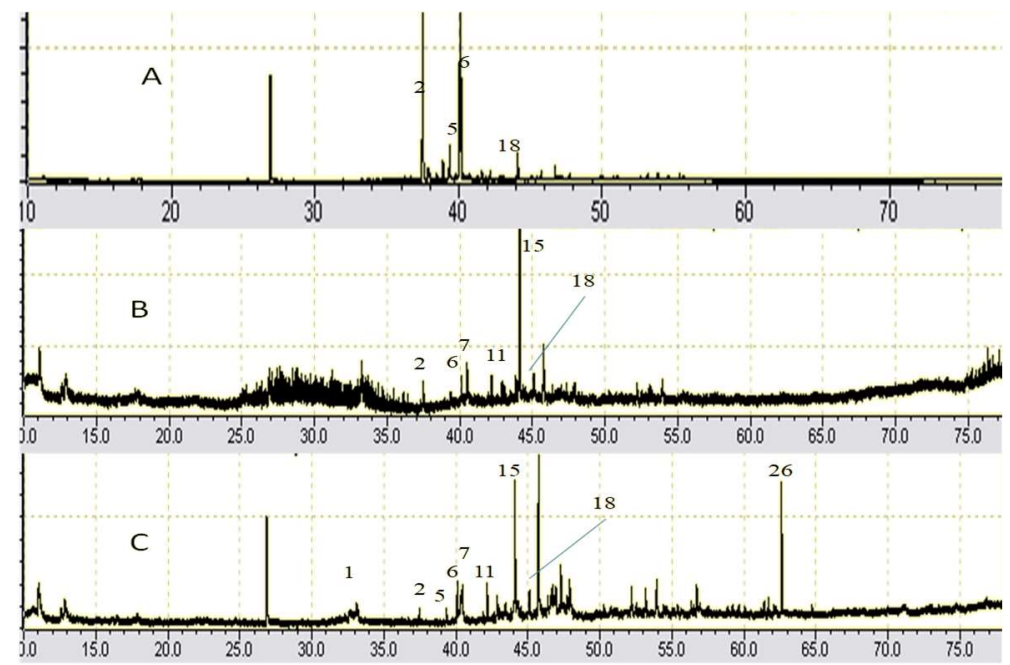

Figura 4: Cromatogramas do íon total dos óleos obtidos das amostras de Inflorescência (A), Folha (B) e Talo (C) de jambu orgânico, cv. Nazaré. (1) Evadone, (2) Dictamnol, (5) Drima-7, 9(11) -diene, (6) Germacrene D, (7) Cis -beta guaiene, (11) Flavesone, (15) Carotol, (18) $\beta$-acorenol, (26) Incensole.

Em jambu cv. Nazaré cultivado de modo orgânico, Germacreno D, pico 6, ocorre em maior intensidade nas inflorescências, seguida das folhas e talos. O composto Dictamol, pico 1, apresenta maior intensidade nas inflorescências e folhas, menor intensidade nos talos, enquanto que Evadone (pico 1) ocorre nos talos e não é observado nas inflorescências e nas folhas, enquanto que o Incensole (pico 26) é observado somente nos talos (Figura 4 A, B, C). Borges et al. (2014), obtiveram 14, 11\% Dictamnol e 7,98 \% Germacrene D, em óleo de essencial de plantas de jambu, cv. Jambuarana.

Verifica-se que de uma forma geral que as cultivares Jambuarana e Nazaré, cultivadas tanto na adubação orgânica e convencional, possuem, na maioria das vezes, os mesmos compostos, mas diferem nas quantidades. Sodré et al. (2012) verificaram que o óleo essencial de Melissa officinalis L. destilado a partir de folhas frescas e secas e cultivada com diferentes doses de esterco bovino e fertilizante mineral, apresentou os mesmos compostos, mas diferentes porcentagens de alguns compostos foram observados. Ming (1992) explica que a fertilização não pode ser dissociada de outros componentes que interferem na planta em desenvolvimento e na produção de óleo essencial e o conteúdo e além de fatores gerais, há fatores ambientais, tais como o microrganismos do solo e estresses sofridos pelas plantas, que podem interferir na rota biosintética dos compostos.

\section{Potencial antifúngico}

O óleo essencial das inflorescência da cv. Nazaré orgânica destaca-se por demonstrar maior atividade contra o fungo Arpergillus nigris 24 hs após sua incubação (Figura 5 - G), quando comparados com as folhas e talos da mesma cultivar cultivada de modo convencional e também quando comparada com a cv. 
Jambuarana, produzidas de forma orgânica e convencional.

Esse resultado pode ser atribuído ao composto Germacreno D, que apresenta em maior intensidade nas inflorescências (Figura 4A). Esse composto por ser um hidrocarboneto, apresenta características lipofílicas acentuadas e de acordo com Burt (2004), os óleos essenciais compreendem um grande número de componentes e seu modo de ação envolve vários alvos.

Os óleos essenciais podem ser uma excelente opção na busca de novo produtos antifúngicos. Sendo uma mistura de vários compostos, eles não agem em alvos específicos nas células de fungos, e, portanto, nenhuma resistência ou adaptação aos óleos tem sido relatada (CARSON et al., 2002). Segundo Dubey et al. (2013) as plantas de jambu podem ter funções antifúngicas, pelas suas propriedades químicas. Para Araújo et al. (2018), em trabalho com extrato hidroetanólico das folhas de jambu, os resultados apresentaram que o extrato é tóxico para as larvas de Ae. aegypti (CL50 11,41ppm).

Além disso, é provável que vários compostos presentes em óleos essenciaiss têm um papel importante na penetração celular, ou como atração lipofílica ou hidrofílico, fixação em paredes de células e/ou membranas, e distribuição celular (BAKKALI et al., 2008). A maioria dos autores considera a lipofilia de seus constituintes como a propriedade que explicaria a atividade antimicrobiana, característica que permitiria a partição destes compostos nos lipídeos da membrana celular e da mitocôndria, aumentando sua permeabilidade e levando ao extravasamento do conteúdo celular (COWAN, 1999).

Isso possivelmente justificaria a atividade antifúngica dos óleos essenciais obtidos nas inflorescências da cv. Nazaré. Segundo Borges et al. (2015), as inflorescências de jambu, são ricas em poliaminas como espermidina e espermina nas substancias relatadas como antioxidante, que pode contribuir para as ações antimicrobianas das plantas de jambu. Franca et al. (2016), realizando avaliação de plantas de jambu, observaram que o ensaio antibacteriano apresentou resultado negativo utilizando amostras in vitro e inibição de bactérias com amostras de campo contra cepas padrão de Staphylococcus aureus (ATCC 29213) e Staphylococcus epidermidis (ATCC 12228).

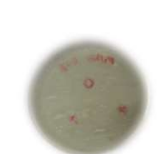

A

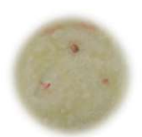

A

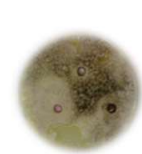

A

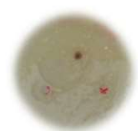

B

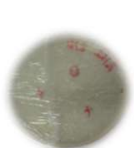

B

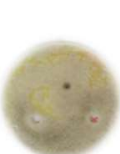

B

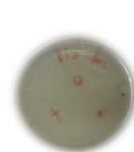

C

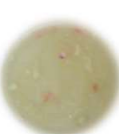

C

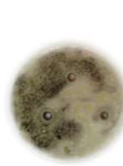

C

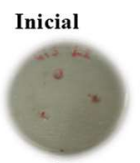

D

24 Horas

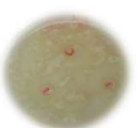

D

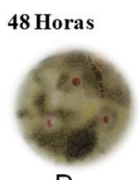

D

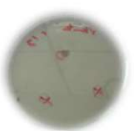

E

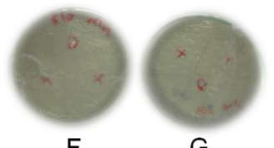

$\mathrm{F}$

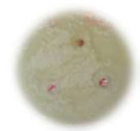

E

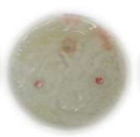

F

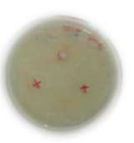

G
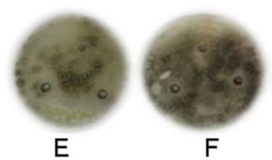

Figura 5: Atividade antifúngica do óleo essencial de jambu, cv. Jambuarana e cv. Nazaré, produzida em adubação orgânica e convencional. (A) Adubação mineral, cv. Jambuarana folha; (B) Adubação mineral, cv. Nazaré folha; (C) Adubação mineral, cv. Jambuarana inflorescência; (D) Adubação mineral, cv. Nazaré inflorescência; (E) Adubação mineral, cv. Jambuarana planta; (F) Adubação orgânica, cv. Jambuarana folha e (G) Adubação orgânica, cv. Nazaré inflorescência. 
A atividade antimicrobiana dos óleos e de alguns de seus componentes já está bem estabelecida. Estes frequentemente apresentam a propriedade de inibir o crescimento de bactérias e fungos, uma vez que servem de defesa contra o ataque de microrganismos nos vegetais (MAGWA et al., 2006; SKOCIBUŠIC et al., 2006).

Segundo outros autores, componentes dos óleos essenciais também podem agir sobre proteínas celulares localizados nas membranas citoplasmáticas, entre elas as ATPases, através de sua acumulação na dupla camada lipídica e consequente destruição da interação lipídeoproteína. Alternativamente, é possível uma interação direta de compostos lipofílicos com porções hidrofóbicas das proteínas (JUVEN et al., 1994; SIKKEMA et al., 1995). Entretanto, devido ao grande número de diferentes grupos químicos presentes nos óleos essenciais, é provável que sua atividade antimicrobiana não possa ser atribuída a um mecanismo de ação específico (SKANDAMIS et al., 2001; CARSON et al., 2002).

\section{CONCLUSÕES}

O óleo de Spilanthes oleracea mostra diferenças entre as cultivares e entre os órgãos estudados, em função de sua fenologia. O maior potencial antifúngico observado foi obtido de inflorescências da cv. Nazaré orgânica. Esta espécie é promissora produtora de óleos essenciais de alto valor agregado.

AGRADECIMENTOS: A CAPES, pela concessão da bolsa.

\section{REFERÊNCIAS}

ADAMS, R. P.. Identificação de essenciais componentes do óleo por cromatografia gasosa/espectro de massametry. 4 ed. Carol Stream: Allured Publ, 2001.

ARAÚJO, I. F.; ARAÚJO, P. H. F.; FERREIRA, R. M. A.; SENA, I. D. S.; LIMA, A. L.; CARVALHO, J. C. T.; FERREIRA, I. M.; SOUTO, R. N. P.. Larvicidal effect of hydroethanolic extract from the leaves of Acmella oleracea L. R. K. Jansen in Aedes aegypti and Culex quinquefasciatus. South African Journal of Botany, v.117, p.134-140, 2018.

ARAÚJO, J. M. A.. Química de alimentos: teoria e prática: óleos essenciais. Viçosa: UFV, 1995.

BAKKALI, F.; AVERBECK, S.; AVERBECK, D.; IDAOMAR, M. Biological effects of essential oils: a review. Food and Chemical Toxicology, v.46, p.446-475, 2008.

BERTOLI, A.; MENICHINI, F.; MAZZETTI, M.; SPINELLI, G.; MORELLI, I.. Volatile constituents of the leaves and flowers of Hypericum triquetrifolium Turrat. Flavour and Fragrance Journal, v.18, p.91-94, 2003.

BLANK, A. F.; FONTES, S. M.; OLIVEIRA, A. S.; MENDONÇA, M. C.; SILVA-MANN, R.; ARRIGONI-BLANK, M. F.. Produção de mudas, altura e intervalo de corte em melissa. Horticultura Brasileira, v.23, n.3, p.780-784, 2005.

BORGES, L. S.; VIEIRA, M. C. S.; VIANELLO, F.; GOTO, R.; LIMA, G. P. P.. Antioxidant compounds of organically and conventionally fertilized jambu (Acmella oleracea). Biological Agriculture and Horticulture, v.31, p.1-10, 2015.

BORGES, L. S.; NUNES, K. N. M.; JACQUES, R. A.; LIMA, G. P. P.. Perfil cromatográfico do óleo essencial de jambu identificados por cromatógrafo a gás acoplado a espectrômetro de massas. Cultivando o Saber, v.7, n.3, p.254-266, 2014.

BORGES, L. S.; GOTO, R.; LIMA, G. P. P.. Índices morfofisiológicos e produtividade de cultivares de jambu influenciadas pela adubação orgânica e mineral. Biosci. J., Uberlândia, v.30, n.6, p.1768-1778, 2014.

BORGES, L. S.; GUERRERO, A. C.; GOTO, R.; LIMA, G. P. P.. Exportação de nutrientes em plantas de jambu, sob diferentes adubações. Semina: Ciências Agrárias, Londrina, v.34, n.1, p.107-116, 2013.

BORGES, L. S.; VIANELLO, F.; MARQUES, M. O. M.; LIMA, G. P. P.. Influence of Organic and Mineral Soil Fertilization and Essential Oil of Spilanthes oleracea cv.Jambuarana. American Journal of Plant Physiology, v.7, p.135-142, 2012.

BURT, S. Essential oils: their antibacterial properties and potential applications in foods-a review. Int. J. Food Microbiol., v.94, p.223-253, 2004.

CAKIR, A.; KORDALI, S.; KILLIE, H.; KAYA, E. . Antifungal properties of essential oil and crude extracts of Hypericum 
linarioides Bosse. Biochemical Systematic and Ecology, v.33, p.245-256, 2005

CARSON, C. F.; MEE, B. J.; RILEY, T. V.. Mechanism of action of Melaleuca alternifolia (tea tree) oil on Staphylococcus aureus determined by time-kill, lysis, leakage, and salt tolerance assays and electron microscopy. Antimicrobial Agents \& Chemotherapy, v.46, p.1914-1920, 2002.

COWAN, M. M.. Plants products as antimicrobial agents. Clin. Microbiol. Rev., v.12, p.564-582, 1999.

DIAS, A. M. A.; SANTOS, P.; SEABRA, I. J.; JUNIOR, R. N.C.; BRAGA, M. E. M.; SOUSA, H. C.. Spilanthol from Spilanthes acmella flowers, leaves and stems obtained by selective supercritical carbon dioxide extraction. The journal of Supercritical Fluids, v.61, p.62-70, 2012.

DUBEY, S.; MAITY, S.; SINGH, M.; SARAF, S. A.; SAHA, S. Phytochemistry, pharmacology and toxicology of Spilanthes acmella: a review. Adv.Pharmacol. Sci., v.2013, 2013.

FRANCA, J. V.; QUEIROZ, M. S. R.; AMARAL, B. P.; SIMAS, N. K.; SILVA, N. C. B.; LEAL, I. C. R.. Distinct growth and extractive methods of Acmellaoleracea (L.) R. K. Jansen rising different concentrations of spilanthol: An important bioactive compound in human dietary. Food Research International, v.89, p.781-789, 2016.

JUVEN, B. J.; KANNER, J.; SCHVED, F.; WEISSLOWICZ, H.. Factors that interact with the antibacterial action of thyme essential oil and its active constituents. J. Appl. Bacteriol, v.76, p.626-631, 1994.

LORENZI, H.; MATOS, F. J. A.. Plantas medicinais do Brasil: nativas e exóticas cultivadas. Nova Odessa, SP: Instituto Plantarum. p.396, 2002.

MAGWA, M. L.; GUNDIDZA, M.; GWERU, N.; HUMPHREY, G.. Chemical composition and biological activities of essential oil from the leaves of Sesuvium portulacastrum. J.

Ethnopharmacol, v.103, p.85-89, 2006.

MAPELI, N. C.; VIEIRA, M. C.; HEREDIA, Z. N. A.; SIQUEIRA, J. M.. Produção de biomassa e de óleo essencial dos capítulos florais da camomila em função de nitrogênio e fósforo. Hortic. Bras., v.23, p.32-37, 2005.

MING, L. C.. Influência de diferentes níveis de adubação orgânica na produção de biomassa e teor de óleos essenciais de Lippia alba (Mill). N.E. br Verbenaceae.

Dissertação (Mestrado em Botânica) - Universidade Federal do Paraná, Curitiba, 1992.

RADULOVIĆ, N.; LAZAREVIĆ, J.; RISTIĆ, N.; PALIĆ, R. Chemotaxonomic significance of the volatiles in the genus Stachys (Lamiaceae): essential oil composition of four Balkan Stachysspecies. Biochemical Systematics and Ecology, v.35, p.196-208, 2007.

SIKKEMA, J.; BONT, J. A.; POOLMAN, B.. Mechanisms of membrane toxicity of hydrocarbons. Microbiol. Mol. Biol. Rev., v.59, p.201-222, 1995.

SIMÕES, C. M. O.; SPITZER, V.. Óleos voláteis. In: SIMÕES, C. M. O.; SCHENKEL, E. P.; GOSMANN, G.; MELLO, J. C. P.; MENTZ, L. A.; PETROVICK, P. R.. Farmacognosia: da planta ao medicamento. Porto Alegre: UFRGS; Florianópolis: UFSC, 1999. p.387-415.

SKANDAMIS, P. N.; NYCHAS, G. J. E.. Effect of oregano essential oil on microbiological and physico-chemical attributes of minced meat stored in air and modified atmospheres. Journal of Applied Microbiology, v.91, n.6, p.1011-1022, 2001.

SKOCIBUŠIC, M.; BEZIC N.; DUNKIC, V.. Phytochemical composition and antimicrobial activities of the essential oils from Satureja subspicata Vis. growing in Croatia. Food Chem, v.96, p.20-28, 2006.

SODRÉ, A. C. B.; LUZ, J. M. Q.; HABER, L. L.; MARQUES, M. O. M.; RODRIGUES, C. R.; BLANK, A. F.. Organic and mineral fertilization and chemical composition of lemon balm (Melissa officinalis) essential oil. Rev.Bras. Farmacogn.Braz. J. Pharmacogn, v.22, n.1, p.40-44, 2012.

TUITE, J.. Plant pathological methods: fungi and bactéria. Minneapolis: Burgess Publish Company, 1969.

ZUZARTE, M.; GONÇALVES, M. J.; CRUZ, M. T.; CAVALEIRO, C.; CANHOTO, J.; VAZ, S.; PINTO, E.; SALGUEIRO, L.. Lavandula luisieri essential oil as a source of antifungal drugs. Food Chemistry, v.135, p.1505-1510, 2012.

WHITFIELD, F. B.. Microbiologically derived off-flavours. In: BAIGRIE, B.. Taints and off-flavours in foods. Cambridge: Woodhead Publishing Limited, 2004.

A CBPC - Companhia Brasileira de Produção Científica (CNPJ: 11.221.422/0001-03) detém os direitos materiais desta publicação. Os direitos referem-se à publicação do trabalho em qualquer parte do mundo, incluindo os direitos às renovações, expansões e disseminações da contribuição, bem como outros direitos subsidiários. Todos os trabalhos publicados eletronicamente poderão posteriormente ser publicados em coletâneas impressas sob coordenação da Sustenere Publishing, da Companhia Brasileira de Produção Científica e seus parceiros autorizados. Os (as) autores (as) preservam os direitos autorais, mas não têm permissão para a publicação da contribuição em outro meio, impresso ou digital, em português ou em tradução. 